\title{
Perspectivas teóricas sobre o Transtorno do Déficit de Atenção/ Hiperatividade (TDAH) e a medicalização da educação
}

\author{
Silla Mescouto Conrado' \\ Antônio Carlos Dias da Encarnação Júnior²
}

Resumo: O presente artigo apresenta uma síntese dos pressupostos teóricos acerca do Transtorno do Déficit de Atenção/Hiperatividade (TDAH), considerando tanto o saber médico quanto o saber à luz da psicologia histórico-cultural. Dentro da perspectiva organicista, é descrito o histórico do TDAH na literatura médica, caracterização, conceituações, etiologia, fisiopatologia, diagnóstico, tratamento medicamentoso e os possíveis riscos do consumo prolongado de substâncias psicoativas por crianças e adolescentes. Contrapondo essa concepção demonstra-se, através dos estudos dos autores da perspectiva historicista, o processo de constituição da atenção voluntária e a natureza social de desenvolvimento desta função psíquica superior, sob condições sociais favoráveis a seu desenvolvimento, possibilitando construir um novo olhar do TDAH. E por fim, frente ao crescimento de diagnósticos relativos às dificuldades de comportamento e de aprendizagem no processo de escolarização, analisa-se o fenômeno da medicalização e seu movimento na educação, permitindo refletir em questões sociais, éticas, políticas, econômicas e práticas pedagógicas.

Palavras-chave: TDAH; perspectivas teóricas; medicalização da educação.

\section{Theoretical perspectives on ADHD and the medicalization of education}

\footnotetext{
Abstract: This article presents a synthesis of the theoretical assumptions about Attention-deficit hyperactivity disorder (ADHD), considering both medical knowledge and knowledge in the light

1 Bacharela em Psicologia e Especialista em Neuropsicologia pela Faculdade Adventista da Bahia (Fadba). Mestranda em Psicologia Clínica e da Saúde pela Universidade Peruana Unión (UPeU). E-mail: silconrado@gmail.com

2 Mestre em Educação e graduado em Pedagogia pela Universidade Federal da Bahia (UFBA). Bacharel em pela Universidade Federal do Recôncavo Bahiano (UFRB). Professor na UFRB. E-mail: antoniocarlos@ufrb.edu.br
} 
of Historical-Cultural Psychology. From the organistic perspective, the history of ADHD, characterization, conceptualizations, etiology, pathophysiology, diagnosis, drug treatment and the possible risks of prolonged use of psychoactive substances by children and adolescents are described in the medical literature. Contrasting this conception, through the studies of the authors from the historicist perspective, the process of constitution of the voluntary attention and the social character of the development of this higher psychic function is demonstrated, in social conditions favorable to its development, making possible the construction of a new vision of ADHD. Finally, given the increase in diagnoses related to behavioral and learning difficulties in the school process, the phenomenon of medicalization and its movement in education is analyzed, allowing reflection on social, ethical, political, economic and pedagogical practices.

Keywords: ADHD; theoretical perspectives; medicalization of education.

Segundo o Manual de Diagnóstico e Estatístico de Transtornos Mentais (DSM-5, 2013), o TDAH constitui um dos problemas de atenção e de controle voluntário do comportamento infanto-juvenil, que se caracteriza por um padrão persistente de desatenção, hiperatividade e/ou agressividade. É um dos transtornos do neurodesenvolvimento mais importantes para a área da neuropsicologia e mais frequente em crianças e adolescentes (PINOCHET-QUIROZ, 2020).

Sofrendo diversas alterações ao longo da história quanto à sua nomenclatura e variações de diagnóstico, ainda não há consenso quanto a sua etiologia entre os pesquisadores adeptos a este constructo teórico, já que existem muitas hipóteses na literatura, "sem que nenhuma delas seja satisfatória em todos os casos" (KEMPER et al., 2018; CONDEMARÍN; GOROSTEGUI; MILICIC, 2014, p. 25).

Contrariando a corrente organicista, pesquisadores adeptos da concepção sócio-histórica de desenvolvimento compreendem o TDAH como "parte de um fenômeno denominado medicalização da educação" (SIGNOR; BERBERIAN; SANTANA, 2017, p. 743). Ponderando e descrevendo sobre isso, este artigo oferece uma síntese teórico-conceitual das vertentes teóricas do TDAH, considerando tanto o saber médico como o saber à luz da psicologia histórico-cultural.

Dentro da perspectiva médica, será descrito o histórico do TDAH na literatura médica; caracterização, conceituações; etiologia, fisiopatologia; diagnóstico, tratamento medicamentoso e os possíveis riscos do consumo prolongado de substâncias psicoativas por crianças e adolescente, já que os estimulantes são a primeira linha para o tratamento, abarcando o grupo do metilfenidato e das anfetaminas (ANVISA, 2014).

No que tange à oposição aos pressupostos organicistas, será apresentado, à luz da psicologia histórico-cultural, o processo de desenvolvimento da atenção voluntária e a natureza social de desenvolvimento dessa função psíquica superior. Esse enfoque teórico não examina a criança como um sujeito isolado, capaz de adaptar-se às condições de vida social, separado do "meio em que se habita", 


\section{Perspectivas teóricas sobre o Transtorno do Déficit de \\ Atenção/Hiperatividade (TDAH) e a medicalização da educação}

do "mundo das coisas", ou do "mundo das pessoas", mas considera o desenvolvimento psíquico das funções superiores do sujeito, como a atenção voluntária, uma conquista humana, desenvolvida por meio da apropriação cultural e mediação do adulto, possibilitando a evolução de funções elementares em direção às superiores (ELKONIN, 1987).

Frente ao crescimento de diagnósticos relativos às dificuldades de comportamento e de aprendizagem no processo de escolarização, este estudo também analisará criticamente o processo de medicalização da educação escolar sob os pressupostos da psicologia histórico-cultural, na problemática que se apresenta na psicologia escolar e educacional na contemporaneidade (CONDEMARÍN; GOROSTEGUI; MILICIC, 2014; BONADIO; MORI, 2013).

Compreendendo as questões complexas que se estabelecem no processo de desenvolvimento humano e de escolarização, temos enfrentado atualmente o desafio de promover o desenvolvimento perante dificuldades defrontadas por nossas crianças em tais processos. Considerando tal demanda, o debate acerca das duas principais construções teórico-metodológicas e conceituais que se apresentam para o enfrentamento de tal problemática é indispensável para a formação acadêmica dos profissionais nesta linha de frente.

Assim, nos debruçaremos acerca de tais pressupostos que, aqui, denominaremos: 1) Perspectivas organicistas; e 2) perspectiva sócio-histórica.

\section{Pressupostos hegemônicos organicistąs para a compreensão de problemas atencionais}

OTDAH, dentro do paradigma médico, constitui-se em uma das patologias mais frequentes em psiquiatria e neurologia infanto-juvenil (CONDEMARÍN; GOROSTEGUI; MILICIC, 2014). Devido a sua alta taxa de prevalência a nível mundial, é considerado uma condição transcultural, se convertendo em um dos principais motivos de procura por serviços especializados e um dos transtornos com maior demanda na área de saúde metal para esse público (PINOCHET-QUIROZ, 2020).

Segundo um estudo epidemiológico de 20 países, realizado pela Organização Mundial de Saúde (OMS, 2017 apud PINOCHET-QUIROZ, 2020), as taxas mais altas de prevalência do TDAH, em crianças e adolescentes, são as dos Estados Unidos $(8,1 \%)$ e as mais baixas encontram-se no Irã $(0,1 \%)$, Polônia (0,3\%) e Romênia (0,4\%). A América Latina e a África apresentam os maiores índices de incidência, uma média de 4,8\% para os países latinos. No Brasil, segundo o boletim brasileiro de avaliação de tecnologias em saúde (ANVISA, 2014), o número de diagnósticos de crianças e adolescentes com TDAH avolumou-se nos últimos anos, oscilando entre 0,9 e $26,8 \%$ de casos diagnosticados. 


\section{Breve histórico do TDAH}

Embora a nomenclatura TDAH seja recente, uma das primeiras menções a essa limitação foi feita na obra do escocês Alexander Crichton, em 1798, o qual a caracterizou como "mental restlessness" (inquietude mental). Posteriomrente o médico psiquiátrico, escritor, ilustrador de contos e alemão Heinrich Hoffmann na sua obra Der Struwwelpeter, publicada em 1846, descreveu em seus contos diferentes problemas e patologias infantis. Já em 1902, George F. Still, pediatra britânico, descreveu, no periódico The Lancet, a sintomatologia desse transtorno em crianças com apresentação de sintomas parecidos com o que hoje se conhece como TDAH (FERNÁNDEZ, 2017; NUNES, 2019).

Segundo George F. Still, o TDAH trata-se de um comprometimento comportamental em crianças com temperamento difícil, inquietas, cruéis, hostis, mentirosas, incapazes de manter a atenção e com dificuldades escolares. Essas descrições são subjetivas, mas são consideradas como o ponto de partida da história científica do TDAH. (FERNÁNDEZ, 2017). O referido pediatra hipotetizou a existência de herança genética ou complicações no parto como sendo originadoras da limitação comportamental. Não sendo possível comprovar a lesão perinatal, começou-se a considerar uma disfunção cerebral, demonstrando dessa forma a fragilidade na pesquisa dos fundamentos do processo de diagnóstico frente a sintomas amplos e indiscriminados (CONDEMARÍN; GOROSTEGUI; MILICIC, 2014; SORBARA, 2017).

No transcurso da literatura médica são observadas constantes mudanças na nomenclatura do TDAH. Em 1947, Alfred Strauss e Heins Werner publicaram uma pesquisa que relacionava sintomas comportamentais hiperativos das crianças a danos cerebrais, mas as evidências foram insuficientes para comprovar essa teoria. Em 1980, a até então lesão cerebral mínima passou a ser denominada pela terceira edição do DSM, da Associação Psiquiátrica Americana (APA), como Transtorno de Déficit de Atenção (TDA), estando subdividido em duas categorias: TDA com hiperatividade e TDA sem hiperatividade (NUNES, 2019).

Em 1993, a Classificação de Transtornos Mentais e de Comportamento (CID-10), da Organização Mundial da Saúde, utilizou o termo "transtornos hipercinéticos", enfatizando o caráter motor do transtorno, seu excesso e dificuldade no controle dos impulsos. Já o DSM-4, em 1994, modificou os termos utilizados novamente, passando a ser chamado de Transtorno de Déficit de Atenção/Hiperatividade, com três subtipos: desatento, hiperativo/impulsivo e combinado, estando estritamente presente antes dos sete anos de idade. Por último, o DSM-5, em 2013, utiliza a mesma terminologia e altera apenas os subtipos, passando a ser chamados de desatento, predominantemente hiperativo/impulsivo ou apresentação combinada (NUNES, 2019; DSM-5, 2013).

\section{O TDAH na contemporaneidade}

Atualmente, a CID-10 e o DSM-5 são os sistemas classificatórios mais utilizados pelos médicos brasileiros para diagnosticar o TDAH. O primeiro foi elaborado pela OMS, tendo em conta que já existe 
a última versão da Classificação Internacional de Doenças (CID-11), que foi lançada em 2018 e entrará em vigor em 2022 (NUNES, 2019). Por outro lado, o DSM-5 foi elaborado pela APA em 2013, apresentando a descrição da sintomatologia, os critérios diagnósticos, fatores de riscos, além de detalhar as muitas expressões da limitação de conduta (DSM-5, 2013).

Não obstante, os dois sistemas classificatórios médicos exijem, além dos critérios de definição diagnóstica, que os sintomas estejam presentes em mais de um ambiente, como escola, casa e comunidade. Os dois apresentam nomenclaturas diferentes e especificidades na caracterização do TDAH. A CID-10 solicita seis ou mais sintomas de desatenção, três ou mais sintomas de hiperatividade e ainda um sintoma de impulsividade, estando presente nos últimos seis meses, todavia manifestados antes dos sete anos de idade. Por outro lado, o DSM-5 classifica a dificuldade comportamental em leve, moderada ou grave. É considerada leve quando os sintomas são somente aqueles necessários para se classificar o diagnóstico; moderada consiste quando o prejuízo funcional estaria entre "leve" e "moderado", e grave seria quando os sintomas ultrapassam a lista dos sintomas necessários para então fechar o diagnóstico médico (NUNES, 2019; DSM-5, 2013).

Conquanto o TDAH seja considerado um transtorno neurocomportamental, quando há a compreensão de haver a interação de fatores herdados, alterações neuroanatômicas e disfunção no sistema de neurotransmissão, influenciando dessa forma os fatores sociais, há, no entanto, grande quantidade de hipóteses etiológicas que coexistem na literatura sobre o TDAH sem, no entanto, nenhuma delas ser satisfatória em todos os casos. Destacam-se entre esses fatores os genéticos, perinatais, infecciosos, toxicológicos, traumáticos, dentre outros (KEMPER et al., 2018; CONDEMARÍN; GOROSTEGUI; MILICIC, 2014).

Por outro lado, o Dr. Bruce D. Perry (BOFFEY, 2014), psiquiatra infantil e neurocientista estadunidense, um dos nomes mais conceituados no mundo na contemporaneidade, sugeriu que o TDAH não é uma doença real. $O$ especialista norte-americano, em encontros com autoridades sanitárias da Inglaterra e publicações em The Guardian e The Observer, disse que estava preocupado pelo fato de crianças estarem sendo rotuladas tendo TDAH, quando isso pode descrever outros problemas fisiológicos (BOFFEY, 2014). Diante disso, percebe-se que há divergência, dentro da perspectiva médica, na compreensão e definição do TDAH, oscilando entre considerá-lo uma enfermidade ou uma singularidade comportamental de crianças e adolescentes.

\section{Processo diagnóstico na perspectiva organicista}

O diagnóstico do TDAH é clínico e subjetivo, considerando o histórico do comportamento do paciente descrito por terceiros (responsáveis e/ou professores) e a ausência de outras enfermidades ou problemas socioambientais para determinar se os critérios descritos no DSM-5 são atendidos (CONDEMARÍN; GOROSTEGUI; MILICIC, 2014; DSM-5, 2013). Alguns médicos psiquiatras acreditam 
que os critérios do DSM-4 foram flexibilizados na versão DSM-5, já que aumentaram a variedade de sintomas avaliados. Enfatizaram a natureza crônica do TDAH e a necessidade de acompanhamento dos sujeitos ao longo dos anos, incluindo, desta maneira, o público adulto, além de permitir a coexistência do transtorno do espectro do autismo com o diagnóstico de TDAH, pois "indivíduos com TDAH e aqueles com Transtorno do Espectro Autista exibem desatenção, disfunção social e comportamento de difícil manejo" (ANVISA, 2014; KEMPER et al., 2018; DSM-5, 2013, p. 64).

Comumente há confusão ou troca no quadro clínico de crianças, adolescentes ou mesmo adultos, já que os sintomas são semelhantes ao quadro clínico do transtorno bipolar, sendo um desafio que requer experiência do profissional que avalia e tempo necessário para se distinguir o TDAH de outros quadros clínicos. Ressalta-se, além do mais, que qualquer pessoa em algum momento se encaixaria em pelo menos alguns critérios (KEMPER et al., 2018; BOFFEY, 2014).

O TDAH geralmente está associado a dificuldades de aprendizagem, tais como discalculia, dislexia, disgrafia; dificuldades articulatórias, alteração no ritmo da fala, qualidade vocal, imprecisões no acesso lexical e no processamento de dados e limitações sintático-semânticas, além de problemas de humor, como ansiedade, depressão, tiques, enurese, estresse pós-traumático, bipolaridade, dentre outros (BONADIO; MORI, 2013; DE PAULA; NAVAS, 2018). Tais aspectos da discussão, relacionados às questões escolares, serão abordados futuramente neste artigo, visto que o crescimento e as críticas às concepções medicalizantes e organicistas do processo de escolarização é tema fundamental na contemporaneidade.

\section{Processo terapêutico na perspectiva organicista}

Quanto às estratégias de tratamento para o TDAH dentro da abordagem médica, são divididas em terapias farmacológicas e não farmacológicas. As terapias farmacológicas incluem estimulantes, inibidores seletivos da recaptação da norepinefrina, alfa-2, agonistas e antidepressivos. As terapias não farmacológicas incluem intervenções psicossociais, intervenções comportamentais, intervenções escolares, terapias de treinamento cognitivo, treinamento de aprendizagem, biofeedback ou neurofeedback, treinamento de comportamento dos pais, suplementos dietéticos (por exemplo, ácidos graxos, ômega-3, vitaminas, suplementos de ervas, probióticos), dietas de eliminação, treinamento de visão e tratamento quiroprático (KEMPER et al., 2018).

Segundo a Associação Brasileira de Saúde Mental (ABRASME, 2014) a prescrição de drogas psiquiátricas a crianças e adolescentes inicia na década de 1980 no Brasil, aumentando significativamente o número de diagnósticos psiquiátricos e de prescrições para essa faixa etária. $\mathrm{O}$ uso de psicoestimulantes é considerado por si só o mais eficaz dos tratamentos nesta concepção teórica, já que tais drogas parecem estimular uma parte do cérebro provocando mudanças nas reações mentais e comportamentais. Podem, também, ajudar a controlar a hiperatividade, a distração, os comportamen- 
tos impulsivos, a atenção focada e o nível de atividade (CONDEMARÍN; GOROSTEGUI; MILICIC, 2014; KEMPER et al., 2018; MACHADO et al., 2015).

No Brasil estão aprovados pela Agência Nacional de Vigilância Sanitária (Anvisa) os seguintes medicamentos para o TDAH: Venvanse ${ }^{\circledast}$ (lis-dexanfetamina), Ritalina ${ }^{\circledR}$ (metilfenidato) e Strattera ${ }^{\circledR}$ (atomoxetina) (ANVISA, 2014). No entanto, o metilfenidato, sendo um estimulante do sistema nervoso central, representa 77 a $87 \%$ de todas as prescrições de estimulantes e pouco se sabe de fato sobre seu mecanismo de ação, mas se acredita que o fármaco inibe transportadores de dopamina e norepinefrina, aumentando a disponibilidade desses neurotransmissores na fenda sináptica (CFF, 2015; NUNES, 2019; ANVISA, 2014).

O metilfenidato chegou ao Brasil em 1998. Em 2009, foram vendidas 557.588 caixas do medicamento, enquanto que, em 2010, esse número foi para 881.959 e em 2011, atingiu a venda de 1.212 .850 caixas vendidas, um aumento de 75\% entre crianças e adolescentes na faixa dos 6 aos 16 anos, no Brasil. Entre abril de 2011 e maio, esse mercado faturou R\$ 101,7 milhões, elevando-o ao posto do psicoestimulante sintético mais consumido no país (ANVISA, 2012; 2014).

Segundo o relatório da Organização das Nações Unidas (ONU) sobre a fabricação de psicotrópicos, a produção mundial passou de 2,8 toneladas em 1990 para quase 48 toneladas em 2011 (ONU, 2015). No Reino Unido, as prescrições da droga metilfenidato, como a Ritalina, aumentaram 56\%, passando de 420.000 em 2007 para 657.000 em 2012 (BOOFEY, 2014). Já nos Estado Unidos, das crianças e adolescentes diagnosticados com TDAH, 2/3 receberam prescrições de estimulantes como Ritalina. Na Inglaterra, o número de drogas prescritas para o TDAH (metilfenidato, incluindo a Ritalina) disparou mais de $50 \%$ em seis anos (ABRASME, 2015).

Diante dos dados acima, pode-se perceber que os médicos e clínicos especialistas na área estão prescrevendo muito rapidamente psicoestimulantes às crianças e adolescentes, quando as evidências apontam que não existem qualquer benefício a longo prazo, criando assim uma falsa epidemia (ABRAS-ME, 2014; BOFFEY, 2014). Contudo, para Mattos, Rohde e Polanczyk (2012), apenas 16,2-19,9\% dos indivíduos com TDAH no Brasil estão recebendo tratamento medicamentoso, enquanto uma porção significativa de pacientes com TDAH está sendo subtratada, caso necessitassem da droga.

Os efeitos adversos associados ao tratamento farmacológico podem incluir mudanças no apetite, supressão do crescimento, alterações na maturação sexual, redução do peso, distúrbios do sono, sintomas gastrointestinais, pressão arterial elevada, aumento da frequência cardíaca, risco de morte cardíaca súbita, arritmias cardíacas, anormalidades de condução, tiques ou outros distúrbios do movimento, mudanças de comportamento, alucinação, agressão, riscos cerebrovasculares (enxaqueca, acidente vascular cerebral, infarto cerebral, vasculite cerebral e isquemia cerebral); podem causar ou agravar problemas psiquiátricos, como depressão, pensamentos suicidas, psicose e mania, já que os 
estudos em animais levantaram preocupações sobre o potencial de danos a serem causados, além do risco de abuso e dependência (KEMPER et al., 2018; EMEA, 2009; BOFFEY 2014; ANVISA, 2014).

O Núcleo de Farmacovigilância do Centro de Vigilância Sanitária do Estado de São Paulo, entre dezembro de 2004 a junho de 2013, recebeu 553 denúncias suspeitas de reações adversas relacionadas ao uso de metilfenidato, tais como: uso não recomendado de metilfenidato em crianças menores de 6 anos; prescrição da droga para depressão, ansiedade e autismo infantil; surgimento de reações adversas graves ao utilizar o metilfenidato, como taquicardia e hipertensão - 37,8\%, psiquiátricas (depressão, psicose e dependência, 36\%), e neurológicas (discinesia, espasmos e contrações musculares involuntárias). Na faixa etária de 14 a 64 anos, as ocorrências graves citadas foram acidente vascular encefálico, labilidade emocional, depressão, pânico, hemiplegia, espasmos, psicose e tentativa de suicídio, dentre outros. Ressalta-se ainda que alguns profissionais prescrevem quantidades de metilfenidato bem acima da recomendada (CFF, 2015; MOTA; DE OLIVEIRA, 2012).

Apesar de todos os efeitos adversos associados ao uso de psicoestimulantes na tentativa de tratar crianças e adolescentes com TDAH descritos acima, a Associação Brasileira de Psiquiatria (ABP, 2014), emitindo a "Carta aberta à população" em protesto à portaria no 986/2014 da Secretaria Municipal de Saúde (SMS) de São Paulo, que passou a restringir e regular a dispensação de metilfenidato no município, disse que o uso de fármacos nos quadros clínicos de TDAH de crianças e adolescentes de baixa renda "fortalece e dá condições de acesso mínimo a recursos de saúde dignos que podem minimizar consequências comportamentais graves com repercussões sociais, psicológicas e educacionais" (ABP, 2014).

Para a Abrasme (2014), "ao se diagnosticar TDAH e prescrever tratamento com drogas psiquiátricas, o que se está promovendo é colocar um número significativo de crianças e adolescentes em uma trajetória que as levará a uma incapacitação por toda a vida", em apoio à Portaria no 989/2014 da SMS de São Paulo. Há inúmeras pesquisas que comprovam e apresentam outras intervenções igualmente eficazes ao longo do tempo, sem, contudo, efeitos secundários adversos à saúde física, social, escolar e psicológica (BOFFEY, 2014).

\section{Perspectiva da psicologia histórico-cultural sobre o TDAH}

Opondo-se à perspectiva médica a respeito do TDAH, à luz da psicologia histórico-cultural, vários pesquisadores, como Leonardo e Suzuki (2016); Ribeiro, Viégas e Oliveira (2019); Aita e Facci (2018); Meira (2012), dentre outros, contestam a visão médica reducionista a respeito das dificuldades de aprendizagem, assim como as de comportamento presente no dia a dia escolar.

Conquanto, nas primeiras décadas do século 20, a psicologia tornara-se uma disciplina científica reconhecida e em crescente processo de institucionalização na América do Norte e em vários países europeus, já que inúmeros estudos sobre capacidades infantis, aprendizagem animal e humana foram desenvolvidos por meio da pesquisa experimental, permitindo grande produção de literatura cientí- 
fica aplicadas à aprendizagem infantil. ${ }^{3}$ Essa psicologia subdividia-se em dois grupos inconciliáveis: de um lado estavam as concepções idealistas da "ciência mental" e de outro estavam as concepções mecanicistas da "ciência natural", sendo que nenhuma delas explanava os fenômenos psicológicos em sua totalidade (VYGOTSKY, 2007). Nesse período, as grandes abordagens da ciência psicológica eram: a psicanálise, o behaviorismo e abordagens fenomenológicas humanistas e existenciais, que por meio de pesquisas visavam prevalecer e criticar umas às outras.

Concomitantemente a esse contexto histórico, Lev Semenovich Vygotski (1896-1934), um jovem desconhecido professor de psicologia bielorrusso, ousou propor uma teoria revolucionária, um constructo teórico que se propunha a abordar a natureza dos processos psicológicos superiores, uma "nova psicologia" embasada no método e nos princípios do materialismo histórico-dialético marxista, na qual se considera como determinante a "cultura historicamente sistematizada pelo trabalho humano, em que o ser orgânico se transforma em ser social" (VYGOTSKY, 2007; MARTINS, 2011, p. 20).

Não se tratava apenas da crítica às grandes abordagens existentes, visto que o trabalho de Vygotsky, bem como de Elkonin, Luria, Leontiev e outros, buscava propor uma ciência psicológica universal, que considerasse os avanços relevantes das abordagens existentes, mas que oferecesse um aporte filosófico e epistemológico que possibilitasse o avanço da produção científica sob uma lógica materialista-histórico dialética, mais complexa e profunda, de modo que efetivamente permitisse a compreensão dos fenômenos humanos em toda sua complexidade.

Nessa perspectiva, o psiquismo humano passa a ser estudado como síntese de um processo de desenvolvimento das funções psíquicas elementares, evoluindo qualitativamente de um funcionamento natural, biológico em direção a um nível culturalmente construído, portanto, superior (TULESKI, 2019).

Para Vygotsky (1995), o comportamento complexo humano é o resultado de dois processos distintos do desenvolvimento psíquico: de um lado, o processo biológico de evolução das espécies animais, funcionando como um sistema interfuncional cortical, e por outro, o processo de desenvolvimento histórico, em que o homem primitivo converte-se em um ser cultural. $\mathrm{O}$ autor destaca que, embora inicialmente separados, a estrutura natural filogenética é a base material para o desenvolvimento pela existência subjetiva em âmbito ontogenético, formando um todo.

\section{0 processo de desenvolvimento humano}

A visão historicista de periodização infantil do desenvolvimento se caracteriza por estar intrinsecamente interligada à situação social de desenvolvimento da criança, na qual o meio ambiente

\footnotetext{
3 Papalia et al. (2013) descrevem seis perspectivas a respeito do desenvolvimento humano, que são: 1) psicanalítica, que foca a dinâmica inconsciente; 2 ) da aprendizagem, que estuda o comportamento observável; 3) humanista, enfatiza o controle dos sujeitos sobre seu próprio desenvolvimento; 4) cognitivista, que analisa os pensamentos; 5) etológica, que considera as bases evolutivas do comportamento; e 6) contextual ou sociocultural, que frisa o impacto do meio histórico, cultural e social.
} 
possibilita os instrumentos e signos culturais, sendo a linguagem o sistema manipulatório dos signos (segundo Vygotsky, "o signo dos signos"), promovendo saltos qualitativos nesse processo de troca e promovendo sua evolução psíquica.

Esse enfoque teórico não examina a criança como um sujeito isolado, capaz de adaptar-se às condições da vida social, separado do "meio em que se habita", do "mundo das coisas", ou do "mundo das pessoas", mas considera indivisível a "unidade existente entre atividade individual, externa e interna, e atividade social (ou coletiva), postulando a dinâmica de internalização como processo de transmutação dos processos interpsíquicos em processos intrapsíquicos" (ELKONIN, 1987; MARTINS, 2011, p. 29).

Segundo Elkonin (1987), o desenvolvimento do psiquismo humano é um processo marcado por crises e saltos que levam a transformações qualitativas, sendo que cada estágio do desenvolvimento infantil se caracteriza por uma relação determinada com a realidade, por um tipo de atividade principal, que denomina de atividade guia. Exercendo essas atividades, as crianças adaptam-se ao meio social, modificam-se, criando e manipulando objetos, visando atender as suas próprias necessidades. Ao mudar o mundo dos objetos, o sujeito muda a si mesmo durante a relação. Desde então, importantes mudanças são produzidas no processo de desenvolvimento psicológico infantil.

\section{A periodização do desenvolvimento e a função psíquica atencional}

Segundo Vygotsky (1995), a atenção primária ou automática ocorre por meio dos mecanismos nervosos herdados, que organizam o curso dos reflexos de acordo com o princípio da fisiologia, caracterizando assim o período de desenvolvimento orgânico de maturação da criança. Por outro lado, a atenção voluntária "é uma das formas pelas quais a percepção se torna consciente, compreendendo, pois, a seleção de dados estímulos, a inibição de seus concorrentes e a retenção da imagem selecionada na consciência" (MARTINS, 2011, p. 114).

Compreendendo que a atenção "depende em alto grau a qualidade da percepção e a organização do comportamento", onde atenção e percepção trabalham em estreita relação frente a milhares de estímulos percebidos pelo sistema sensório-perceptual, o processo de seletividade, que seria a "imagem captada", ocorre mediante a um complexo processo de desenvolvimento (MARTINS, 2011, p. 112). Ponderando essas informações, a seguir discutiremos as etapas de desenvolvimento à luz da compreensão psicológica historicista, relacionando-as paralelamente ao desenvolvimento da função psíquica atencional.

Os principais estágios nessa perspectiva de desenvolvimento são: a primeira infância, que se subdivide em comunicação emocional do bebê (de zero a aproximadamente um ano, em condições promotoras para esse desenvolvimento) e atividade objetal manipulatória (de um ano até aproxima- 
damente três anos); jogo de papéis; atividade de estudo; comunicação íntima pessoal e atividade profissional/estudo, sendo que nesta discussão, serão brevemente abordados os cinco primeiros estágios.

Na primeira etapa, o primeiro ano de vida da criança pré-linguístico, após o final da crise pós-natal, seguida dos reflexos condicionados e da orientação até o adulto, aproximadamente no terceiro mês, surge o "complexo de animação". Posteriormente, aparece a etapa de pegar as coisas, em que o bebê, em condições promotoras de desenvolvimento, é estimulado pelo adulto e orientado pela observação visual, dirige a mão aos objetos. A atenção nesse momento é fisiologicamente primária; caracteriza-se por ter um foco principal de excitação que inibe o curso de outros estímulos, propiciando o desenvolvimento orgânico dos aparatos nervosos do bebê, e, assim, adaptando-o ao meio. É nesse momento que o desenvolvimento cultural da atenção tem seu início, quando ainda o recém-nascido tem o primeiro contato social com os adultos ao seu entorno (ELKONIN, 1987; VYGOTSKY, 1995).

A crise do primeiro ano é marcada pela utilização de instrumentos e o emprego de palavras para demostrar desejos e insatisfações, surgindo a linguagem autônoma infantil, que se difere da linguagem adulta já que a criança utiliza uma palavra para se referir a um conjunto de coisas e os adultos nomeiam com palavras, por outro lado, carregadas de significados e articuladas foneticamente (PASQUALINI, 2009).

A fase objetal manipulatória é caracterizada pelo surgimento da linguagem autêntica e a percepção generalizada dos objetos, que antes era difusa e caótica, permitindo à criança estabelecer relações significativas com o meio social. Dessa forma, com a fala e os signos incorporados à ação, a criança passa a utilizar instrumentos especificamente humanos, que, segundo Vygotsky (2007, p. 20), "é o momento de maior significado no curso do desenvolvimento intelectual", pois, por meio da fala, juntamente com os olhos e as mãos, a criança resolve suas atividades práticas, controla o ambiente e o próprio comportamento. É também nessa etapa que pode surgir a crise dos três anos, caso tenham sido oferecidas condições sociais e históricas para esse desenvolvimento, em que a criança busca por autonomia e independência. Considerando esses avanços, na linguagem e percepção, surge a consciência, isto é, a criança tem compreensão verbal dos objetos e de sua própria conduta (PASQUALINI, 2009).

Sobre essa etapa, Elkonin (1987, p. 163) ressalta que "o domínio dessas ações é, evidentemente, impossível sem a participação dos adultos para demonstrarem às crianças e estas executarem as ações com eles", sendo então necessária a mediação do adulto nesse processo de apresentação dos objetos. A comunicação que antes era emocional passa a ter um caráter mais prático, isto é, a criança utiliza a linguagem como meio para contatos "de trabalho" com o adulto. Diante dessas considerações, a atividade principal da criança nessa fase do desenvolvimento psicológico é a objeto-instrumental, na qual "tem lugar a assimilação dos procedimentos socialmente elaborados de ação com os objetos" (ELKONIN, 1987, p. 163). 
Sobre esse momento no curso do desenvolvimento infantil, Luria (2010, p. 90) diz que o comportamento de crianças de um ano e meio a dois é marcadamente desestruturado e desordenado, em contraste com as de três a quatro anos e meio, que apresentam os primeiros sinais de atenção organizada, pois "a criança começa a escolher objetos particulares no mundo exterior e neles fixar seu olhar e, se é que se pode usar este termo, neles fixar seu comportamento total".

Esse grande salto no desenvolvimento psíquico infantil, isto é, o conhecimento dos objetos e sua exploração por meio da atividade objetal manipulatória, será seguido por uma nova etapa, a fase pré-escolar. Nesta, a brincadeira de "faz de conta" é a principal atividade, pois "a criança modela, no jogo, as relações entre as pessoas", desenvolvendo assim novas habilidades atencionais, já que necessita lembrar-se dos papéis, não podendo distrair-se (ELKONIN, 1987, p. 164; EIDT; TULESKI; FRANCO, 2014). Para Leontiev (2010), a infância pré-escolar é o principal momento de preparação para a aprendizagem escolar, período em que a realidade humana se abre para a criança, permitindo-lhe adentrar ao mundo dos objetos humanos, assimilando-o e reproduzindo as ações humanas.

Martins (2011, p. 121) ressalta que, sob condições favoráveis à internalização de signos nesta etapa, "a atenção mediada revelará seus primeiros indícios, apontando conexões, ainda que incipientes, entre estímulos externos e operações internas", abrindo caminho para os próximos anos, em que os meios externos poderão ser utilizados adequadamente a fim de enriquecer a qualidade atencional como uma atividade externa. Segundo a mesma autora, essas atividades perdurarão ao longo de toda a idade escolar até a adolescência, gerando significativas mudanças na qualidade da atenção, sendo que o grau desse desenvolvimento condiciona-se estreitamente ao desenvolvimento do pensamento por conceitos, possibilitando que a atenção alcance seu estágio superior.

Ao adentrar a fase escolar, que em nossa cultura é denominado Primeiro Ciclo do Ensino Fundamental, a criança poderá apresentar raciocínio lógico, linguagem coordenada, percepção mais generalizada, memória reorganizada sobre a lógica do pensamento verbal, além de poder fixar conteúdos voluntariamente. É necessário destacar que a criança poderá encontrar-se nessas condições caso seu desenvolvimento tenha sido promovido para tal em suas condições sociais e históricas. A criança, portanto, poderá passar a ter obrigações não somente para com os pais e professores, mas com a sociedade cujo cumprimento dependerá de sua situação na vida, suas funções e papéis sociais e, por isso, o conteúdo de toda a sua vida futura (LEONTIEV, 2010). A atividade guia desse período é a atividade de estudo, na qual as primeiras noções na área do conhecimento em geografia, ciências naturais, história e outras áreas curriculares passam a compor o processo de ensinagem escolar.

Elkonin (1987, p. 165) ressalta que nessa fase ocorre "uma intensa formação das forças intelectuais e cognoscitivas da criança", pois a atividade escolar requer que ela assimile objetos e informações que não lhe interessam totalmente e de imediato, exigindo desta maneira que oriente e sustente a atenção em objetos essenciais à atividade envolvida. Por outro lado, a criança escolar ainda não tem 
total controle sobre sua atenção, necessitando, por sua vez, da mediação do adulto, do professor, para direcioná-la ao essencial, facilitando a correlacionar pontos importantes nas temáticas da atividade que estuda (EIDT; TULESKI; FRANCO, 2014). A perda da espontaneidade caracteriza a crise dentro desse período, sendo conhecida como a crise dos sete anos. A partir desse momento, a criança valora sua própria posição no contexto social, dando sentido às suas próprias vivências (PASQUALINI, 2009).

$\mathrm{Na}$ idade de transição (de onze a dezesseis anos, aproximadamente) ou adolescência, com a continuidade da atividade de estudo juntamente com a comunicação íntima, a atenção interna, voluntária, poderá consolidar-se, e isso só é possível mediante a passagem do pensamento em complexos, que corresponde a um longo percurso (desde o término da primeira infância até o início da adolescência) de conexões práticas e casuais, para o pensamento conceitual, quando então a criança alcança seu alto grau de abstração, atendendo desta maneira as exigências da vida adulta (MARTINS, 2011).

Desta forma, percebe-se que a atenção voluntária inicia seu processo de desenvolvimento "com o primeiro gesto indicativo, com ajuda do qual os adultos tentam dirigir a atenção da criança e com o primeiro gesto independente da criança, com o qual começa a dirigir a atenção dos outros". Nesse processo, ela depende tanto em sua formação como em sua consolidação, dos meios em que a sociedade ou os modos educativos a organizam a fim de percorrer seu curso de desenvolvimento de nível elementar como atenção involuntária, para um nível superior, a atenção voluntária (VYGOTSKY, 1996; apud EIDT; TULESKI; FRANCO, 2014, p. 82).

\section{Posicionamento político da psicologia histórico-cultural frente ao suposto TDAH}

Tecidas essas breves considerações a respeito da periodização infantil e a formação cultural da atenção voluntária, em que "a atenção imediata, natural, se transforma por apropriação de signos externos, em atenção mediada; a atenção mediada se requalifica pela conversão dos signos externos em signos internos", conclui-se que "a atenção voluntária tem origem em motivos e finalidades estabelecidos conscientemente pelo indivíduo em face das exigências das atividades empreendidas". Dessa forma, "seu desenvolvimento é, ao mesmo tempo, produto da complexificação da vida social e condição indispensável à sua existência" (MARTINS, 2012, p. 121-122).

É necessário destacar, portanto, que a psicologia histórico-cultural não coaduna com a existência de um transtorno nos processos atencionais humanos, visto que a atenção concentrada é uma função psíquica superior forjada sócio-historicamente como complexificação de suas bases biológicas. Tal função não pode ser vista como pronta, doente ou "transtornada", mas em processo de desenvolvimento que, caso não haja condições sociais favoráveis e promotoras desse desenvolvimento, compromete-se o tempo e o efetivo desenvolvimento dessa função. Definir as dificuldades no processo de escolarização "como sendo decorrentes de problemas individuais de aprendizagem ou com- 
portamento anula a experiência concreta, desconsidera o contexto, dando à queixa uma aparência de que ela independe das condições sociais e históricas" (RIBEIRO; VIÉGAS; OLIVEIRA, 2019, p. 192-193).

Portanto, tratar crianças que não contaram com condições promotoras desse desenvolvimento, às quais foram negadas condições de segurança afetiva, linguística, simbólica e/ou educacional, com o uso de drogas psicoestimulantes como o metilfenidato é um atentado contra a própria humanidade. É uma prova de que o humano sequer sabe e domina conceitual e simbolicamente o seu próprio processo de fazer-se e fazer-nos homens na história de vida de cada sujeito humano, pois "a humanização só pode se concretizar quando, em contato com o mundo objetivo e humanizado, transformado pela atividade real de outras gerações e por meio da relação com outros homens, o homem aprende a ser homem" (MEIRA, 2012, p. 136).

Considerando tais princípios fundamentais da perspectiva histórico-cultural do desenvolvimento humano, partiremos para as críticas ao processo de medicalização na esfera educacional, que se sustenta na biologização e naturalização do que não é nem biológico e nem natural. Especificamente quanto ao TDAH, a concepção hegemônica parte do pressuposto equivocado de que a função psíquica atencional em nível superior deve estar pronta e desenvolvida em crianças em idade escolar, caso contrário há um transtorno de déficit de atenção (AITA; FACCI, 2018). Tal concepção desconsidera a obviedade da impreterível qualidade das condições materiais de mediação e apropriação histórica e cultural dessa criança, que, não tendo seu desenvolvimento promovido adequadamente pelos adultos responsáveis, paga o preço ao ser-lhe atribuído um suposto transtorno e no uso de medicamentos psiquiátricos (LEORNADO; SUZUKI, 2016).

\section{A medicalização da educação}

Nas sessões anteriores foram abordadas duas perspectivas teóricas a respeito do TDAH: a médica biologizante, que conceitua como doença as dificuldades atencionais e de controle voluntário do comportamento infanto-juvenil; e a histórico-cultural, que considera o desenvolvimento psíquico da atenção voluntária como uma conquista humana, sendo desenvolvida por meio da apropriação cultural e mediação do adulto, possibilitando a evolução de funções elementares a superiores em condições propícias para tal desenvolvimento. Partindo desse pressuposto, de que a atenção voluntária necessita de condições favoráveis a seu desenvolvimento, pesquisadores adeptos à concepção historicista compreendem o TDAH como "parte de um fenômeno denominado medicalização da educação" (SIGNOR; BERBERIAN; SANTANA, 2017, p. 743).

O termo medicalização surgiu pela primeira vez na obra Nêmesis médica (1975), do filósofo austríaco Ivan Illich, fazendo referência à colonização da medicina institucionalizada que transcendia os limites reais e éticos da própria ação médica, que, por outro lado, além de denunciar o imperialismo médico, defendia uma política de saúde que recuperasse a autonomia pessoal e a ética nos tratamentos médi- 
cos (CASTILHA, 2015; BIANCHI, 2019). Nesse aspecto, como dito anteriormente, destacamos a crítica de correntes de pensamento psiquiátrico à flexibilização diagnóstica na versão do DSM-5, ressaltando que qualquer pessoa se encaixaria em tais critérios em algum momento da vida (BOFFEY, 2014).

Para Bianchi (2019), a medicalização é um fenômeno complexo, global, heterogêneo, multifacetado, em desenvolvimento, marcado por conflitos e debates. Embora composta por diferentes abordagens teórico-metodológicas, na contemporaneidade o discurso medicalizante apresenta uma dinâmica diferenciada, já que não incide da mesma maneira, nem com a mesma intensidade em muIheres, homens, ricos, pobres, crianças e adultos, atuando, em contrapartida, de maneira peculiar em diferentes regiões e países do mundo (BIANCHI, 2019).

A tecnologia é a força impulsionadora, já que cria mercados e atrai novos consumidores de saúde; a genética e a indústria farmacêutica são subcampos de estudos, voltadas para expandir as novas descobertas. Ressalta-se também a acessibilidade e a disponibilidade a tecnologias biológicas, incluindo medicamentos, instrumentos diagnósticos e outros equipamentos, assim como o acesso a inúmeras informações sobre enfermidades e transtornos (AZEVEDO, 2018). Trata-se, pois, da criação de supostas doenças que incluem cada um de nós em nichos de mercado consumidor de exames, publicações, fármacos, consultas, que mantêm o mercado da indústria da doença sempre aquecido em detrimento à promoção da saúde real da sociedade. Filosoficamente, passa-se a pensar a saúde como bem a ser comprado e consumido e não condição normativa da vida humana.

A profissão médica, dentro desse cenário, possui um lugar destacado, pois além de propagar o discurso medicalizante, "induz os indivíduos a adotarem determinadas formas de viver, pensar e se comportar", codificando o sofrimento mental e promovendo uma epidemia diagnóstica (AZEVEDO, 2018, p. 7; BIANCHI; FARAONE, 2015). Por outro lado, observa-se o constante crescimento das descobertas no campo das neurociências, na revolução psicofarmacológica, nas ciências biomédicas, na compreensão dos transtornos e tratamentos psiquiátricos e o aumento desenfreado dos casos de incapacitação por psicopatologias.

A partir dessa breve conceituação sobre medicalização, tal fenômeno alia-se à busca social por alívio rápido e imediato ao sofrimento humano, em que não se procura o enfrentamento adequado para certas dificuldades ou enfermidades humanas, mas sim remédios como solução na esperança de resolver e salvar as pessoas de suas angústias, sem, no entanto, o conhecimento dos efeitos danosos do uso de fármacos no organismo. Portanto, são deslocados para o campo da medicina problemas de origem social e política, convertendo e biologizando fenômenos humanos, como tristeza e insônia, em sintomas e doenças mentais (SANTANA; GONÇALVES, 2019). Desse modo, o movimento de crítica à medicalização abarca fenômenos como: medicalização do parto, da alimentação, dos sentimentos e emoções, medicalização da sexualidade, de aspectos étnico-raciais; medi- 
calização da vida saudável e outras esferas da vida cotidiana. No entanto, neste artigo, apenas nos debruçamos à medicalização da educação.

Conquanto a medicina tenha uma larga história de tradição no uso de estimulantes para o tratamento de uma ampla gama de condições, incluindo estados nervosos, desde a década de 1950, os fármacos se converteram em um aspecto central no tratamento psiquiátrico (BIANCHI; FARAONE, 2015). No entanto, foi em 1937 que um grande experimento, ou melhor, ostracismo, foi realizado pelo neurologista norte-americano Bradley com crianças e adolescentes institucionalizados, dando-lhes calmantes e anfetaminas, drogas estas já conhecidas por seus efeitos colaterais e dependência química em adultos. Suas experiências, sem rigor metodológico, resumiram-se em dizer que "usando anfetaminas, todas as crianças com problemas de comportamento ou aprendizagem apresentaram melhora significativa e persistente de todos os sintomas", justificando, desse momento, a prescrição médica de drogas a crianças e adolescentes (MOISÉS; COLLARES, 2011, p. 140).

Outro momento importante na expansão do discurso medicalizante à infância foi o medo de que os Estados Unidos estivessem ficando atrás da antiga União Soviética na corrida pela superioridade científica, tecnológica e militar durante o período da guerra fria (1945-1991). Desde então, a preocupação de educadores e cidadãos com a qualidade dos programas educacionais do país e com o futuro das próximas gerações originou grandes mudanças na educação norte-americana, elevando sobremaneira os padrões acadêmicos nas escolas. Nesse momento, crianças dos subúrbios e das favelas foram submetidas a elevadas exigência escolares, sendo rotuladas de ter problemas de aprendizagem e de comportamento (SMITH, 2014).

Dessa maneira, percebe-se que por trás do discurso orientado à prevenção, à saúde mental, às políticas educativas que legitimam a intervenção médica no campo privado, nas relações familiares e na criação das crianças, está um caso considerado clássico de expansão e migração global de diagnóstico medicalizado, o TDAH. Nesse contexto, múltiplos fatores sociais, políticos, econômicos e tecnológicos contribuíram para fazer com que comportamentos antes vistos como bastantes normais se transformassem em um transtorno psiquiátrico infantil (BIANCHI, 2019; SMITH, 2014). Ressalta-se que nessa mesma época, em 1944, foi sintetizado pelo laboratório CIBA o metilfenidato, logo indicado para a antiga disfunção cerebral mínima (BIANCHI; FARAONE, 2015).

A busca por maior rendimento, eficiência e eficácia humana no período, que se estendeu das esferas laborais, acadêmicas e até mesmo militares seguiu em direção à vida cotidiana, invadindo a noção coletiva de normalidade. Em uma sociedade "normatizadora", os indivíduos deveriam se encaixar em um padrão extremamente restrito, não havendo margem para as diferenças humanas; contudo, ninguém se encaixa pela vida inteira.

Assim, na esfera educacional, por exemplo: crianças tímidas se encaixam em diagnósticos de distimia; crianças extrovertidas são vistas como verborrágicas; as que brincam demais são desaten- 
tas; as que dificilmente brincam são as traumatizadas. Todas elas se encaixam em diagnósticos: as agressivas têm transtorno opositor desafiante; as que são boas em matemática têm asperger, mas as ruins têm discalculia; as que têm letras feias têm disortografia; as que falam mal têm dislalia, e assim, sempre há um diagnóstico para cada um de nós. No processo histórico, a concepção hegemônica medicalizante transformou as diferenças humanas em doenças e problemas de diferentes ordens em "transtornos" e "distúrbios" (GROFF; SOUZA, 2020). Como obviamente todos nós somos diferentes por natureza, todos nós, agora, nos encaixamos em algum tipo de desvio normativo, compondo, assim, uma sociedade de doentes construída histórica e culturalmente por uma sociedade adoecedora.

Esse curto histórico da expansão da medicalização para o campo infanto-juvenil, aparentemente coincidindo com a criação do metilfenidato, embasa os primórdios da fisiopatologia e nosologia dos transtornos de comportamento e de aprendizagens em crianças e adolescentes, que originou o quadro sintomatológico do TDAH. Dessa forma, o TDAH nasce sob o discurso da cientificidade e objetividade, sem, no entanto, nenhuma comprovação científica de sua existência ou etiologia orgânica que o explique além de parâmetros descritivos (MOISÉS; COLLARES, 2011; CASTILHA, 2015).

Buscando identificar precocemente transtornos mentais infantis em crianças que antes eram consideradas mal-educadas, indisciplinadas e desmotivadas, os manuais diagnósticos, "irrompendo o ideal de uma 'criança perfeita' associado diretamente à saúde, cujas imperfeições devem ser mapeadas e evitadas tanto quanto possível", procuram padronizar o comportamento infantil (AZEVEDO, 2018, p. 7). Nesse sentido, tem havido forte adesão dos pais à medicalização das dificuldades dos filhos, na medida em que se busca a explicação médica e a cura do comportamento infantil. A escola, por outro lado, quando enfatiza os aspectos biomédicos das dificuldades dos alunos, deixa para segundo plano aspectos relacionais e pedagógicos, passando a ocupar um papel ativo no processo de medicalização, ao mesmo tempo que se exime e se inocenta da própria responsabilidade (SANTANA; GONÇALVEZ, 2019).

Segundo Bonadio e Mori (2013), a prática de medicar crianças e jovens em razão de questões escolares foi difundida no Brasil desde o século 20, ganhando força no século 21, quando a escola solicita, cada vez mais, a presença de médicos, psicólogos, fonoaudiólogos e psicopedagogos para fornecer diagnósticos e tratamento a questões escolares, instalando questões médicas em situações não médicas. Dessa forma, "a medicalização tem biologizado os processos educacionais, transformado boa parte das problemáticas educacionais em questões de saúde e ainda despolitizando as reais demandas da educação básica ao culpabilizar o estudante pelas dificuldades no processo de ensinar e aprender" (GROFF; SOUZA, 2020, p. 34).

Na lógica de culpabilização, é importante destacar que sob a égide da lógica medicalizante, a culpa pelos problemas de escolarização recai nos mais diversos indivíduos envolvidos no processo. Isso acontece, no entanto, sempre seguindo a mesma lógica medicalizante: quando a culpa é investi- 
da à família, é por ser desestruturada; se é investida aos pais, é porque são negligentes; se é investida à professora, é porque ela é mal formada ou negligente; se é investida na criança, é porque tem algum transtorno, déficit ou distúrbio. Assim, a lógica de culpabilização é um dos componentes ideológicos embutidos na medicalização da educação e da sociedade.

Dentro desse cenário, a psicologia consolidou os conceitos biológicos de educação mantidas pela pedagogia, sendo isolado o caráter social do processo educacional, no qual padrões de desenvolvimento foram estabelecidos no intuito de "classificar os aptos dos não aptos, e assim aqueles que não se enquadravam às medidas, eram considerados alunos problemas" (BONADIO; MORI, 2013, p. 93). Nesse sentido, o TDAH é explicado por seus defensores como um fenômeno genético, originado por desequilíbrio neurobioquímico na região frontal do cérebro, causando comportamentos inadequados e inadaptados dentro do contexto escolar, mas que, por outro lado,"gera um esvaziamento do papel do professor como aquele capaz de interferir, numa dimensão prático-simbólica, nos processos de aprendizado e desenvolvimento das crianças" (NUNES, 2019; SANTANA; GONÇALVEZ, 2019, p. 827). Assim, a concepção medicalizante dos problemas de aprendizagem engessa a atuação e responsabilização da geração adulta na promoção do desenvolvimento infantil e esconde as reais condições sociais e históricas desse desenvolvimento eventualmente limitado por condições adversas e distantes das ideias, em detrimento de explicações biologizantes e patologizantes dos comportamentos humanos.

\section{Considerações finais}

Diante do exposto no decorrer deste artigo, buscou-se apresentar duas perspectivas teóricas a respeito do TDAH: a concepção médica biologizante e patologizante, que considera como doença qualquer dificuldade de atenção e de controle voluntário, receitando como principal tratamento o uso de drogas psicoestimulantes, embora não exista nenhum indicador patognomônico que comprove a sua existência e tampouco um exame que o determine como doença; e a perspectiva teórica psicológica sócio-histórica, que, por compreender que a atenção voluntária é desenvolvida mediante a interação e apropriação cultural mediada pelos adultos ao desenvolver as funções elementares qualitativamente a um nível superior, acredita que as condições sociais promovem, ou não, o desenvolvimento da atenção voluntária. Portanto, tais dificuldades de atenção e de controle voluntário seriam resultantes de processos de desenvolvimento ainda em construção, que precisam ser promovidos e não medicados.

Considerando a exclusividade médica ao formular diagnóstico nosológico para perturbações e distúrbios do corpo, uma concepção engessada e divulgada como suprema verdade na sociedade, além de poder omitir condições que podem ser semelhantes em aparência ao TDAH (por exemplo, ansiedade, atraso na fala ou linguagem, doenças médicas, dentre outras), contribui para o crescimento do número de diagnóstico de TDAH e de requisições de estimulantes 
ao longo dos anos, expondo crianças e adolescentes ao uso de "pílulas milagrosas". Tal concepção vem favorecendo a grande soma de lucro de grandes indústrias farmacêuticas, sem alterar comportamentos indesejáveis como a negligência dos adultos com crianças e adolescentes e a intolerância ante incômodos modos de ser (KEMPER et al., 2018; ABRAS-ME, 2014).

Este artigo sinaliza, assim, a controvérsia referente à medicalização da educação, em que há a transferência de questões sociais, históricas e culturais para a esfera médica, isentando da responsabilidade "as instituições de poder em cujas entranhas são gerados e perpetuados tais problemas". O presente estudo teórico, no entanto, não abordou a existência de quadros clínicos em que crianças e adolescentes apresentam reais comprometimentos em seu desenvolvimento cognitivo, que, por outro lado, necessitam da intervenção psicofarmacológica (MOISÉS; COLLARES, 2011, p. 134).

Diante da problemática apresentada neste estudo, tornam-se necessárias novas concepções que abordem contextos de formação à questão da medicalização da educação, debatendo questões éticas, teóricas, técnicas, perspectivas pedagógicas e psicológicas, processos educativos e práticas pedagógicas, refletindo, desse modo, sobre questões psicossociais, políticas e econômicas. Considerando que a ciência psicológica e seus profissionais têm sido convocados historicamente para atuar nos problemas de escolarização, destacamos a relevância desta temática em toda a sua complexidade no processo de formação do psicólogo e profissionais das diversas áreas que abarcam a educação.

\section{Referências}

AITA, E. B.; FACCI, M. G. D. Trastorno de Déficit de Atención e Hiperatividade y el proceso de biologizaciób y medicalización de las quejas escolares. Eureka, Assunção, v. 15, n. 1, p. 121-135, 2018. Disponível em: https://bit.ly/35DC0uO. Acesso em: 15 maio 2021.

ARAÚJO, R. C.; SANTOS, I. S. TDAH no contexto escolar: fracasso escolar ou sucesso do sujeito. Disponível em: https://bit.ly/3qjixsP. Acesso em: 10 jun. 2020.

ASSOCIAÇÃO BRASILEIRA DE PSIQUIATRIA. Carta aberta à população. 2014. Disponível em: https://bit. ly/3vLclLh. Acesso em: 17 jun. 2020.

ASSOCIAÇÃO BRASILEIRA DE SAÚDE MENTAL (ABRASME). Transtorno de déficit de atenção e hiperatividade (TDAH) e a iniciativa exemplar da SMS de São Paulo. 2014. Disponível em: https://bit. ly/3zGx9qt. Acesso em: 10 jul. 2020.

AZEVEDO, L. J. C. Considerações sobre a medicalização: perspectiva cultural contemporânea. CES PSICO, Rio de Janeiro, v. 11, p. 1-12, 2018. Disponível em: https://bit.ly/3cXtXNF. Acesso em: 17 ago. 2020.

BONADIO, R. A. A.; MORI, N. B. R. Transtorno de déficit de atenção e hiperatividade: diagnóstico e práticas pedagógicas. Maringá: Abeu, 2013. Disponível em: https://bit.ly/3j0aMXk. Acesso em: jan. 2020. 
BRASIL. Agência Nacional de Vigilância Sanitária (ANVISA). Boletim Brasileiro de Avaliação de Tecnologias em Saúde (BRATS). Metilfenidato no tratamento de crianças com transtorno de déficit de atenção e hiperatividade, Brasília, v. 8, n. 23, mar. 2014. Disponível em: https://bit.ly/2SdYL5q. Acesso em: 03 jul. 2020.

BRASII. Agência Nacional de Vigilância Sanitária (Anvisa). Boletim de Farmacoepidemiologia, Brasília, ano 2, n. 2, p. 1-14, jul.-dez. 2012. Disponível em: https://bit.ly/3gl6Qsp. Acesso em: 01 jun. 2020.

BIANCHI, E. ¿De qué hablamos cuando hablamos de medicalización? Sobre adjetivaciones, reduccionismos y falacias del concepto en ciencias sociales. Revista latinoamericana de metodología de las ciencias Sociales, v. 9, n. 1, p. 1-24, jun.-nov. 2019. Disponível em: https://bit.ly/3wML9NI. Acesso em: 28 nov. 2020.

BIANCHI, E.; FARAONE, A. S. El Transtorno por Déficit de atención e hiperactividad (TDA/H). Revista de saúde coletiva, Rio de Janeiro, v. 25, n. 1, p. 25- 98, 2015. Disponível em: https://bit.ly/35UA8y9. Acesso em: 20 ago. 2020.

CASTILHA, C. J. L. La Medicalización de la infancia en salud mental: el caso paradigmático de los trastornos de atención. Papeles del psicólogo, v. 36, n. 3, p. 174-18, 2015. Disponível em: https://bit.ly/2Sg99cV. Acesso em: 29 nov. 2020.

CONDEMARÍN, M.; GOROSTEGUI, E. G.; MILICIC, N. Déficit atencional: estrategias para el diagnósticos y la intervención psicoeducativa. 5 ed. Buenos Aires: Ariel, 2014.

CONSELHO FEDERAL DE FARMACIA (CFF). Protocolo de uso de metilfenidato: restrição da liberdade de prescrição e do acesso ou busca do uso racional? A discussão em torno da Portaria $n^{\circ}$ 986-SMS.G, de São Paulo, de 12 de junho de 2014, Boletim Farmacoterapêutica, 2015. Disponível em: <https://bit. ly/3qdfH8R>. Acesso em: 18 jun. 2020.

DE PAULA, E. M. S.; NAVAS, A. L. Caracterização das alterações de leitura em crianças com transtorno do déficit de atenção e hiperatividade: revisão de literatura. Revista Cefac, v. 20, n. 6, p. 785-797, nov.-dez. 2018. Disponível em: https://bit.ly/2UrZKjr. Acesso em: 14 ago. 2020.

EIDT, N.; TULESKI, S.; FRANCO, A. Atenção não nasce pronta: o desenvolvimento da atenção voluntária como alternativa à medicalização. Nuances: estudos sobre educação, Presidente Prudente, SP, v. 25, n. 1 , p. 78-96, jan.-abr. 2014. Disponível em: https://bit.ly/3xDjIWG. Acesso em: 27 jul. 2020.

ELKONIN, D. Psicologia Evolutiva e Pedagógica na URSS: Antologia. In: ELKONIN, D. Sobre o problema da periodização do desenvolvimento psíquico na infância. Moscú: Editorial Progreso, 1987, p. 149-171.

EUROPEAN MEDICINES AGENCY (EMEA). European Medicines Agency makes medicines recommendations for safer use of Ritalin and other methylphenidate-containing in the EU. Press office, Londres, jan. 2009. Disponível em: https://bit.ly/3wQgqPK. Acesso em: 18 ago. 2020.

FERNÁNDEZ, G. V. F. Prehistoria del TDAH: aditivos para un diagnóstico insostenible. Papeles del psicólogos, v. 38, n. 2, p. 107-115, 2017. Disponível em: https://bit.ly/2TSvGNz. Acesso: 10 fev. 2021.

KEMPER, A. R. et al. Attention Deficit Hyperactivity Disorder: diagnosis and treatment in children and adolescents. Comparative effectiveness review, n. 203, p. 1-120, 2013. Disponível em: https://bit. Iy/3wXIINy. Acesso em: 10 jun. 2020. 


\section{Perspectivas teóricas sobre o Transtorno do Déficit de Atenção/Hiperatividade (TDAH) e a medicalização da educação}

LEONARDO, N. S. T.; SUZUKI, M. A. Medicalização dos problemas de comportamento na escola: perspectivas de professores. Revista de psicologia, v. 28, n. 1, p. 46-54, jan.-abr. 2016. Disponível em: https://bit.ly/3iVw9J5. Acesso em: 10 maio 2021.

MACHADO, F. S. N. et al. Uso de metilfenidato em crianças com transtorno de déficit de atenção e hiperatividade. Ver saúde pública, v. 49, n. 32, p. 1-5, 2015. Disponível em: https://bit.ly/3cZ3DTc. Acesso em: 20 jul. 2020.

MANUAL DISGNÓSTICO E ESTATÍSTICO DE TRANSTORNOS MENTAIS (DSM-5). American psychiatric association. 5 ed. Porto Alegre: Artmed, 2013.

MARTINS, L. O desenvolvimento do psiquismo e a educação escolar: contribuições à luz da psicologia histórico-cultural e da pedagogia histórico-crítica. Interface - comunicação, saúde, educação, São Paulo, v. 16, n. 40, p. 19-38, 2012. Disponível em: https://bit.ly/35Cx7lQ. Acesso em: 10 jul. 2020.

MATTOS, P.; ROHDE, L. A.; POLANCZYK, G.V. ADHD is undertreated in Brazil. Revista brasileira de psiquiatria, n. 34, p. 513-516, 2012. Disponível em: https://bit.ly/3iZf94E. Acesso em: 15 jun. 2020.

MEIRA, E. M. M. Para uma crítica da medicalização na educação. Revista de Psicologia Escolar e Educacional, São Paulo, v. 16, n. 1, p. 135-142, -. Disponível em: <https://bit.ly/3qgCJvx>. Acesso em: 10 maio de 2021.

FACCI, M. G. D, et al. A exclusão dos "incluídos: uma crítica da Psicologia da Educação à patologização e medicalização dos processos educativos. In: MOISÉS, M. A. A.; COLLARES, C. A. L. O lado escuro da dislexia e do TDAH. Maringá: Eduem - UEM, 2011, p. 133-195.

MOTA, D. M; DE OLIVEIRA, M. G. Prescrição e consumo de metilfenidato no Brasil: identicando riscos para o monitoramento e controle sanitário. 2012. Boletim de farmacoepidemiologia do SNGPC. Disponível em: https://bit.ly/3qgEVD2. Acesso em: 18 jun. 2020.

NUNES, M. E. N. Caracterização do diagnóstico e tratamento do transtorno de déficit de atenção e hiperatividade (TDAH) realizada por uma amostra de neurologistas infantis brasileiros. 2019. 120 ff. Dissertação (Mestrado Profissional em Medicina) - Faculdade de Medicina, Universidade de São Paulo, Ribeirão Preto, 2019. Disponível em: https://bit.ly/3vFftbL. Acesso em: 10 jul. 2020.

OLTRAMARI, L. C.; FEIROSA, L. R. C.; GESSER, M. Psicologia Escolar e Educacional: processos educacionais e debates contemporâneos. In: GROFF, A. R.; SOUZA, S. V. Práticas medicalizantes: contribuições da psciologia educacional na formação inicial e continuada de docentes. Florianópolis: Edições do Bosque, 2020, p. 33-53.

ONU. Report of the international narcotics control board for 2015. Disponível em: https://bit. ly/2SIsfJb. Acesso em: 11 out. 2020.

PAPALIA, D. E.; FELDMAN, R. D. Desenvolvimento humano. 12 ed. Porto Alegre: Artmed, 2013.

PASQUALINI, J. A perspectiva histórico-dialética da periodização do desenvolvimento Infantil. Psicologia em estudo, Maringá, v. 14, n. 1, p. 31-40, 2009. Disponível em: https://bit.ly/3cWFE74. Acesso em: 16 out. 2020.

PERRY, B. D. In.: BOFFEY, D. Children's hyperactivity 'is not a real disease', says US expert. The Guardian, Londres, 30 mar. 2014. Disponível em: https://bit.ly/35FJeyv. Acesso em: 18 jun. 2020. 


\section{Perspectivas teóricas sobre o Transtorno do Déficit de Atenção/Hiperatividade (TDAH) e a medicalização da educação}

PINOCHET-QUIROZ, P. et al. Propiedades psicométricas del inventario CABI para la determinación del TDAH. Rev. Ecuat. de Neurol., Talca, Chile, v. 29, n. 3, p. 31-39, 2020. Disponível em: https://bit.ly/3vEMfcY. Acesso em: 15 maio 2021.

RIBEIRO, M. I. S.; VIÉGAS, L. S.; OLIVEIRA, E. C. O diagnóstico de TDAH na perspectiva de estudantes com queixa escolar. Revista práxis educacional, Vitória da Conquista, Bahia, v. 15, n. 36, p. 178-201, 2019. Disponível em: https://bit.ly/3wMHWNV. Acesso em: 09 maio 2021.

SANTANA, C. G. C.; GONÇALVEZ, L. R. Educação, patologização e medicalização: é possível quebrar essa corrente? Educação em foco: revista de educação, Juiz de Fora, Minas Gerais, v. 24, n. 3, p. 827-848, dez. 2019. DOI: https://bit.ly/35E531t. Acesso em: 15 out. 2020.

SÃO PAULO. Secretaria Municipal da Saúde. Portaria Secretaria da Saúde - SMS n 986, de 11 de junho DE 2014. Disponível em: https://bit.ly/3gSEgU3. Acesso em: 10 out. 2020.

SIGNOR, R. C. F.; BERBERIAN, A. P.; SANTANA; A. P. A medicalização da educação: implicações para a constituição do sujeito/aprendiz, Educação e Pesquisa, v. 43, n. 3, p. 743-763, 2017. Disponível em: https://bit.ly/3h6djN9. Acesso em: 15 jun. 2020.

SMITH, M. The hyperactive state: ADHD in its historical context. Londres, 2014. Disponível em: https:// bit.ly/3j5QJGG. Acesso em: 15 set. 2020.

SORBARA, G. Geração psicoestimulantes: problemas pedagógicos e políticos, Revista on-line de política e gestão educacional, Araraquara, n. 2012, p. 48-60. Disponível em: https://bit.ly/3glEPBa. Acesso em: 08 set. 2020.

TULESKI, S. A unidade do psiquismo humano para vigotski e a desagregação desta na esquizofrenia. Psicologia: teoria e pesquisa, Brasília, v. 35, p. 1-11, 2019. Disponível em: https://bit.ly/3wNkvEa. Acesso em: 17 nov. 2020.

VYGOTSKY, L. S. Obras escogidas. Tomo III. In: VYGOTSKY, L. S. Dominio de la atención. Madrid: Visor, 1995, p. 212-245. Disponível em: <https://bit.ly/2SU0IUV>. Acesso em: 12 nov. 2020.

VIGOTSKI, L. S. A formação social da mente. 7 ed. São Paulo: Martins Fontes, 2007.

VIGOTSKI, L. S.; LURIA, A. R.; LEONTIEV, A. N. Linguagem, desenvolvimento e aprendizagem. In: LEONTIEV, A. R. Uma contribuição à teoria do desenvolvimento da psiqui infantil. 11 ed. São Paulo: Ícone, 2010, p. 59-83.

VIGOTSKI, L. S.; LURIA, A. R.; LEONTIEV, A. N. Linguagem, desenvolvimento e aprendizagem. In: LURIA, A. R. A psicologia experimental e o desenvolvimento infantil. 11 ed. São Paulo: Ícone, 2010, p. 85-102. 